\title{
Should we regularly evaluate the neurodevelopmental status of moderate and late preterm infants?
}

Son Moon Shin, MD

Department of Pediatrics, Inje University Busan Paik Hospital, Busan, Korea

\section{Key message}

Recent studies have shown higher risks of neurodevelopmental delay and behavioral problems in moderate and late preterm infants.

It is important to closely monitor the neurodevelopmental status and provide early intervention in referred cases.

For long-term follow-up, selection criteria are needed to identify the target population among moderate and late preterm infants.

The preterm birth rate has increased from $2.8 \%$ of total live births in 1995 to $8.6 \%$ in $2018,{ }^{1)}$ with a simultaneous increase in, both, moderate and late preterm (MLPT) births, those occurring at 32-33 weeks and at 34- to 36-week gestation, respectively.

The neurodevelopmental risks of very preterm infants have been well recognized; however, studies of the neurodevelopmental outcomes of MLPT infants have been reported over the last two decades. ${ }^{2-4)}$

The fetal brain weight at 34 -week gestation is only $65 \%$ of the weight at 40 -week gestation. ${ }^{5)}$ Thus, the last few weeks of gestation are important for brain maturation. The brain of the preterm infant has to grow, mature, and adapt to the extrauterine environment after birth, and the interruption of this natural process may affect the infant's neurodevelopment.

In recent issue of Clinical and Experimental Pediatrics, Jin et al. ${ }^{6}$ reported on the long-term outcomes of MLPT infants at school age. Of their MLPT population, 24.3\% had a borderline intelligence function and memory quotient, 32.4\% had a borderline executive quotient, $13.5 \%$ had internalizing problems, and $66.7 \%$ had an abnormal score for at least one variable for attention deficit hyperactivity disorder.

$\mathrm{Vohr}^{2)}$ and Natarajan and Shankaran ${ }^{3)}$ reviewed studies of the long-term neurodevelopmental outcomes of MLPT infants at school age. They reported that MLPT children were at an increased risk of developmental, language, and cognitive delays at school age, showed poorer school performance, and were more likely to need special education for behavioral problems. A meta-analysis of cognitive development and behavioral problems indicated an increased incidence of internalizing or externalizing behavior and a higher prevalence of attention problems in MLPT children.7)

Bogičević et al. ${ }^{8)}$ reported that Weschler Full Scale and Verbal Intelligence Quotient scores of 6-year-old MLPT children were lower than those of their full-term peers, a phenomenon that can be predicted by a toddler's skills at 24 months of age.

Putnick et al. ${ }^{9)}$ assessed language performance from 5 months to 8 years of age and reported that MLPT children had poorer performance than that of their full-term peers, a difference that was stable from 20 months to 8 years. They suggested that language performance at the end of the second year is highly predictive of later language performance and claimed that physicians must refer MLPT infants for early intervention whenever they recognize language delays.

As Vohr ${ }^{2}$ suggested, the close surveillance of MLPT children's neurodevelopmental status and early referral of those demonstrating a neurodevelopmental delay is important.

The study of Jin et al. ${ }^{6}$ had some limitation. Specifically, it lacked a full-term peer control group and included only neonatal intensive care unit graduates, who had medical complications and were at higher risk than their counterparts who did not require intensive care were in. However, it called attention to the importance of surveillance of the neurobehavioral development of MLPT children.

MLPT births comprised $90.1 \%$ of total preterm births in Korea in 2018. ${ }^{1)}$ The need for long-term follow-up for MLPT infants increases the burden on medical facilities. As Favrais and Saliba ${ }^{4)}$ suggested, we must determine the selection criteria for long-term follow-up of MLPT infants or a screening policy that identifies the targeted population using developmental screening tests based on parental response. In Korea, infants and children 4-71 months of age have been screened annually since 2007 through the National Health Screening Program for Infants and Children. As part of the health screening program, neurodevelopmental screening is performed annually from 9 months of age until a child's sixth birthday. Infants and children born between 2008 and 2009 were screened with the Korean version of the Ages and Stages Questionnaire, a neurodevelopmental screening test, through the national health screening

Corresponding author: Son Moon Shin, MD. Department of Pediatrics, Inje University Busan Paik Hospital, Bokji-ro 75, Busanjin-gu, Busan 47392, Korea 凶E-mail: smshinmd@hanmail.net, https://orcid.org/0000-0002-3743-3307

Received: 25 March, 2020, Revised: 17 May, 2020, Accepted: 22 May, 2020

This is an open-access article distributed under the terms of the Creative Commons Attribution Non-Commercial License (http://creativecommons.org/licenses/bync/4.0/) which permits unrestricted non-commercial use, distribution, and reproduction in any medium, provided the original work is properly cited.

Copyright (c) 2020 by The Korean Pediatric Society 
Table 1. Results of the Korean version of the Ages and Stages Questionnaire for infants and children born between 2008 and 2009

\begin{tabular}{|c|c|c|c|}
\hline Age (mo) & Preterm & Full term & $P$ value \\
\hline $9-12$ & & & 0.0001 \\
\hline Normal & 21,866 (85.94) & 373,448 (91.38) & \\
\hline Follow-up ${ }^{\text {a) }}$ & 2,562 (10.07) & $23,389(5.79)$ & \\
\hline Refer ${ }^{\mathrm{b})}$ & 1,016 (3.99) & $7,399(1.83)$ & \\
\hline $18-24$ & & & 0.0001 \\
\hline Normal & $25,944(87.53)$ & $436,555(92.45)$ & \\
\hline Follow-up & 2,342 (7.90) & $24,974(5.29)$ & \\
\hline Refer & $1,353(4.56)$ & 10,701 (2.27) & \\
\hline $30-36$ & & & 0.0001 \\
\hline Normal & 27,215 (86.69) & $460,596(91.60)$ & \\
\hline Follow-up & $2,196(7.00)$ & $25,731(5.12)$ & \\
\hline Refer & 1,981 (6.31) & 16,531 (3.29) & \\
\hline $42-48$ & & & 0.0001 \\
\hline Normal & $26,063(84.60)$ & $441,393(90.02)$ & \\
\hline Follow-up & $2,114(6.86)$ & 26,054 (5.31) & \\
\hline Refer & 2,630 (8.54) & $22,879(4.67)$ & \\
\hline $54-60$ & & & 0.0001 \\
\hline Normal & $24,182(81.04)$ & $416,650(87.41)$ & \\
\hline Follow-up & $2,329(7.80)$ & $29,763(6.24)$ & \\
\hline Refer & 3,329 (11.16) & $30,264(6.35)$ & \\
\hline $66-71$ & & & 0.0001 \\
\hline Normal & $21,552(80.03)$ & $374,671(85.82)$ & \\
\hline Follow-up & 2,446 (9.08) & $32,579(7.46)$ & \\
\hline Refer & 2,933 (10.89) & $29,349(6.72)$ & \\
\hline
\end{tabular}

Values are presented as number (\%).

${ }^{a}$ Follow-up was performed for any child whose score in a particular area was close to the cutoff point. ${ }^{b)}$ Referral was made for any child whose score in one or more areas was below the established cutoff point.

Boldface indicates a statistically significant difference with $P<0.05$.

program. As higher refer rates were consistently observed in prematurely born children (Table 1), they were at a higher risk of developmental delay than were their full-term peers.

In 2015, a new developmental screening test based on parental response, the Korean Developmental Screening Test for Infants and Children (K-DST), was developed and launched in the National Health Screening Program for Infants and Children. ${ }^{10)}$ About $75 \%$ of infants and children who were born in Korea, including preterm infants, have since been screened annually by the K-DST as a part of the national health screening program. All children are provided with annual screening opportunities by the K-DST; furthermore, MLPT children must be evaluated and monitored by pediatric neurologists or psychiatrists according to a standardized protocol if they show any signs of developmental delay or behavioral problems.

The proper analysis of the neurodevelopmental evaluation data of MLPT referred cases will provide the basis for selection criteria for the further evaluation of and early intervention for MLPT infants and children.

\section{Conflicts of interest}

No potential conflict of interest relevant to this article was reported.

See the article "Long-term cognitive, executive, and behavioral outcomes of moderate and late preterm at school age" via https:// doi.org/10.3345/kjp.2019.00647.

\section{References}

1. Korean Statistical Information Service. Vital statistics from Korean Statistical Information Services. Birth statistics according to the gestational period. Population prospects study, 1995-2018 [Internet]. Daejeon (Korea): Statistics Korea; [cited 2020 Mar 20]. Available from: http:// kosis.kr/eng/statisticsList/statisticsListIndex.do?menuId=M_01_01\& vwcd=MT_ETITLE\&parmTabId=M_01_01\&statId=1962004\&the mald $=\#$ SelectStatsBoxDiv.

2. Vohr B. Long-term outcomes of moderately preterm, late preterm, and early term infants. Clin Perinatol 2013;40:739-51.

3. Natarajan G, Shankaran S. Short- and long-term outcomes of moderate and late preterm infants. Am J Perinatol 2016;33:305-17.

4. Favrais G, Saliba E. Neurodevelopmental outcome of late-preterm infants: literature review. Arch Pediatr 2019;26:492-96.

5. Guihard-Costa AM, Larroche JC. Differential growth between the fetal brain and its infratentorial part. Early Hum Dev 1990;23:27-40.

6. Jin JH, Yoon SW, Song J, Kim SW, Chung HJ. Long-term cognitive, executive and behavioral outcomes of moderate and late preterm at school age. Clin Exp Pediatr 2020 Feb 6 [Epub]. https://doi.org/10.3345/ kjp.2019.00647.

7. Bhutta AT, Cleves MA, Casey PH, Cradock MM, Anand KJ. Cognitive and behavioral outcomes of school-aged children who were born preterm: a meta-analysis. JAMA 2002;288:728-37.

8. Bogičević L, Verhoeven M, van Baar AL. Toddler skills predict moderateto-late preterm born children's cognition and behaviour at 6 years of age. PLoS One 2019;14:e223690.

9. Putnick DL, Bornstein MH, Eryigit-Madzwamuse S, Wolke D. Longterm stability of language performance in very preterm, moderate-late preterm, and term children. J Pediatr 2017;181:74-9.e3.

10. Yim CH, Kim GH, Eun BL. Usefulness of the Korean Developmental Screening Test for infants and children for the evaluation of developmental delay in Korean infants and children: a single-center study. Korean J Pediatr 2017;60:312-9. 